\title{
Teachers' Perspectives on Addressing Linguistic Factors Affecting Visualisation of Mathematics Word Problems
}

\author{
Matshidiso Mirriam Moleko ${ }^{1 *}$ \\ 1 University of the Free State, SOUTH AFRICA
}

Received 18 March 2021 - Accepted 17 September 2021

\begin{abstract}
Visualisation plays a critical role in the teaching and learning of mathematics word problems. It is an essential tool for enabling learners to create meaningful mental pictures necessary for solving mathematical problems. Appropriate visualisation requires good reading skills, English proficiency and an understanding of mathematical vocabulary, language and structure. Although visualisation plays such a critical role, teachers often do not pay attention to linguistic factors when teaching mathematics word problems, thus making it difficult for learners to visualise and solve mathematics word problems. This background positions the study to explore teachers' perspectives on the linguistic factors that affect the visualisation of mathematics word problems and to identify appropriate solutions to these. Using a single-case exploratory study, the perspectives of six mathematics teachers were elicited through focus group discussions and reflection sessions. The data collected were analysed through thematic analysis techniques. The findings indicate strategies to address the lack of reading skills, including understanding mathematical language and the structure and ambiguities of mathematics word problems.
\end{abstract}

Keywords: critical emancipatory research, linguistic factors, mathematics word problems, visualisation

\section{INTRODUCTION}

Mathematics word problems are defined as problems representing real-life contexts (Verschaffel et al., 2010). These problems require an understanding of mathematical language and language proficiency (i.e., learners' ability to use the language to make meaning and to communicate meaning verbally and in writing during the teaching and learning process), which most learners, especially those who use the language of learning and teaching (LoLT) as a second language, seem to lack (Demirsoy, 2020). Solving word problems is one of the key components of mathematics education that incorporate real-life problems and application (Ahmad et al., 2010). Learning how to solve word problems involves knowledge about semantic construction, mathematical relations and knowledge of elementary numerical skills and strategies (Sajadi et al., 2013).

Word problems provide many benefits when taught to learners, including how to relate and apply the content learnt in class to real-life contexts (Larina, 2016), assisting in developing their skills in logical analysis (Charles, 2011) and boosting their creative thinking (Lince, 2016). According to many researchers, although word problems provide such colossal benefits, learners have reportedly expressed great difficulties in understanding and solving these problems (Demirsoy, 2020; Mulwa, 2015; Nickson, 2000; Phonapichat et al., 2014). In the context of this study, word problems are mathematical problems that are written in words, depicting real-life scenarios or situations, which, in order to be solved, learners first need to read, understand and make sense of so that they eventually are able to translate them into algebraic mathematical expressions or equations that are easy to solve.

Previous research has highlighted several challenges pertaining to the teaching and learning of word problems. These challenges include an inability to form number sentences to represent the mathematics involved in word problems (Gooding, 2009), a lack of English proficiency (Essien, 2013), an insufficient grasp of mathematical vocabulary knowledge (Sepeng, 2014).

(c) 2021 by the authors; licensee Modestum. This article is an open access article distributed under the terms and conditions of the Creative Commons Attribution License (http://creativecommons.org/licenses/by/4.0/). 


\section{Contribution to the literature}

- This paper contributes to the literature on mathematics teachers' perspectives on the role of visualisation in the teaching and learning of mathematics word problems.

- The study provides useful ways in which the linguistic factors impeding the visualisation of mathematics word problems can be addressed.

- The study contributes to the literature that shows interconnectedness between visualisation, language and mathematics, thus proposing a linguistics-focused mathematics word problem teaching approach.

On the other hand, the role of visualisation in improving the teaching and learning of word problems has also been highlighted by previous research (e.g., Kurshumlia \& Vula, 2013; Osman et al., 2018). Although visualisation plays an important role in mathematics (Yilmaz \& Argun, 2018) and in the teaching of word problems (Carden \& Cline, 2015), there is a paucity of research that explores the linguistic factors that affect the visualisation of word problems and provide solutions based on teachers' perspectives. According to Klerkx et al. (2014), there is a need for more research to be conducted on visualisation to improve mathematics problem solving. Echoing the same sentiment, Kim (2020) stresses the need for visualisation as one of the features of the new approach to teaching mathematics to be embraced as a promising and sustainable instructional model for supporting learners in terms of accessing conceptual understanding in mathematics classrooms. Ziemkiewicz et al. (2012) as well recommend that more research on visualisation in mathematics teaching and problem solving should be conducted in order to identify which individual factors are relevant to visualisation with the motive to confirm the factors already found and to investigate new factors. The findings of this study will thus contribute to the expansion of the literature on mathematics teaching approaches by proposing a linguistic-focused approach to enhance the visualisation of word problems.

\section{Visualisation}

According to Harvey and Goudvis (2007), visualising word problems refers to learners' ability to create pictures in their heads based on the text they read or the words they hear. These authors claim that visualisation reinforces reading comprehension skills, as learners gain a more thorough understanding of the text they are reading by consciously using the words to create mental images. Visualising a word problem means to comprehend the problem in terms of a visual (mental) image, and in line with this, visualisation is regarded as a process that involves visual imagery, with or without a diagram, and is deemed an essential part of the method of solution (Shatri \& Buza, 2017).

Visualisation has been found to be useful in terms of enabling learners to successfully solve word problems (Teahen, 2015). Yilmaz et al. (2018) describe the role of visualisation as developing inductive, deductive, and proportional reasoning skills, which are much needed when engaging in solving word problems. These authors regard visualisation as a central component of the many cognitive processes and attribute the essentiality thereof to the transformation in thinking from concrete to abstract. Gambrell and Jawits (1993) note that learners who are able to construct mental images from what they are reading tend to develop a better understanding of the concepts compared to those who are not able to visualise word problems. De Koning and Van der Schoot (2013) avow that learners who are inclined to make mental images when engaged in solving word problems tend to be more proficient readers. Making mental images thus enables learners to remember and connect story (i.e., the word problems story) elements and to concretise complex and abstract ideas from the text (Algozzine \& Douville, 2004).

Moreover, visualisation has been found to be a useful tool in terms of triggering learners' imagination and deepening their understanding of word problems (Shatri \& Buza, 2017). Osman et al. (2018) point out that visualisation helps to improve learners' thinking skills. Nwachukwu (2017) reiterates that developing learners' visualisation skills is an important task of the teacher towards fostering greater comprehension and conceptualisation of word problems. Based on the abovementioned information, a deduction can be made that visualisation plays an essential role in facilitating an understanding of word problems; consequently, teachers have a role to play in this process, in terms of applying teaching strategies that seek to promote visualisation in order to reinforce understanding. The meaning of visualisation in the context of this study is informed by definitions provided by De Koning and Van der Schoot (2013), Algozzine and Douville (2004) and Gambrell and Jawits (1993). In short, visualisation refers to the process of making appropriate mental images when reading word problems, which subsequently enables readers (in this context, learners) to convert word problems into simple, equivalent, solvable algebraic equations and expressions.

\section{Visualisation Techniques}

According to Gallenstein (2005), one way to enhance visualisation is by using concrete representations, which, in turn, assist learners in developing mathematical concepts by manipulating concrete objectives physically. 
Concrete representation promotes visualisation, which, in turn, assists in simplifying complex mathematical concepts (Cease-Cook, 2013). Concrete representations in the form of physical objects (e.g., manipulatives) or visual images (e.g., diagrams) enhance visualisation and thus enable learners to represent mathematical concepts and ideas and to conceptualise abstract ideas in realworld situations (e.g., word problems). According to Gerofsky (2009, p. 36), concrete representations "have the potential to offer memorable imagery that can act as a touchstone for teachers and learners in building and discussing abstract concepts".

Mulligan and Mitchelmore (2009) avow that pictorial representations (those that learners create as well as those that are produced with the problem and presented to the learners) can help learners visualise the abstract mathematics relationships that are embedded in word problems. As part of supporting learners, Bakar (2017) too encourages drawing representations to scaffold visualisation and an understanding of emerging concepts in mathematics. Nonetheless, evidence shows that interpreting others' representations can be difficult, especially for young learners (Frick \& Newcombe, 2015). Consequently, Flevares and Perry (2001) advise teachers to support learners in terms of learning to interpret representations by providing "effective transitional experiences" (Boulton-Lewis, 1998, p. 222) to support their progression to using these different representations. This means that teachers have to use scaffolding visualisation techniques that will enable learners to use and interpret the different representations. Ding and Li (2014), however, caution about over-reliance on the use of concrete representation as a teaching strategy, since it has the potential to hinder learning. They thus suggest using this strategy in conjunction with others.

Even though visualisation plays such an important role in the teaching and learning of mathematics, research shows that it is one of the tools that have often been neglected or avoided and are less frequently used (Mooney et al., 2014). Boonen et al. (2016) add that teachers often teach word problems in ways that do not promote visualisation, thereby making it difficult for learners to conceptualise and solve these problems. For this reason, Mooney et al. (2014) advise that teachers should strive to adapt their teaching strategies to promote visualisation. In line with this, the study reported in this paper sought to explore the linguistic factors that affect the visualisation of word problems and to identify solutions to address the identified challenges.

The study thus responded to the following research questions:

- What are the language factors that affect the visualisation of word problems and the related challenges thereof?
- How can the challenges pertaining to the identified language factors be addressed to enhance the visualisation of word problems?

\section{Teachers' Perceptions on Linguistic Issues Regarding Word Problem Solving}

The majority of the township and rural schools in South Africa officially use English as the language of learning and teaching and for assessment purposes, regardless of the fact that learners in these schools often are not proficient in English (Taylor \& Vinjevold, 1999). Teachers in these schools find it difficult to teach learners word problems and often attribute challenges to learners' lack of reading skills, English proficiency, writing skills and struggle to comprehend texts that are written in English (Mayaba, 2009). According to Huang and Normandia (2008), teachers attribute the common mistakes that learners make when solving word problems to the fact that these problems require not only knowledge of mathematical calculations but also linguistic knowledge, which learners often lack. Teachers also attribute the difficulty of solving word problems to learners' inability to identify keywords, define vocabulary, analyse long sentences and comprehend written context (Gafoor \& Sarabi, 2015; Seifi et al., 2012). Some teachers claim that solving word problems is affected by variables such as mathematical language use, text comprehension and terminology, comprehending operations entrenched in the text, the clarity of concepts and vocabulary and the structure of the word problem (Kunene \& Sepeng, 2017). Fatmanissa and Kusnandi (2017) maintain that teachers' understanding of linguistic aspects of word problems is important as it leads to an understanding of helping learners to face the challenges of this mathematical genre.

\section{Theoretical Framework}

The study adopted critical emancipatory research (CER) which is a transformative paradigm aimed at promoting active participation, knowledge sharing and empowerment (Tsotetsi, 2013). Researchers who adopt this lens believe in the idea of collective wisdom towards the formulation of strategies to address the identified issues or areas of concerns (Mahlomaholo, 2009). Within a CER framework, the participants' voices are regarded as significant to inform the desired change (Dold \& Chapman, 2011). In this study, teachers were requested to take part in the research project, as their experience in and knowledge of teaching were deemed important to suggest ways in which the visualisation of word problems could be enhanced. 


\section{RESEARCH METHODS}

\section{Research Design and Methodology}

The single-case exploratory study reported in this paper followed a qualitative approach of a descriptive and explanatory nature. Qualitative research is a method used to collect data using a naturalistic approach and helps to unearth trends in thought and opinions and dive deeper into the problem (Creswell, 2009; Denzin \& Lincoln, 2005) by focusing on the meaning the participants accredit to their actions (Aspers \& Corte, 2019). A descriptive and explanatory qualitative approach enables research participants to provide their perspectives and share their experiences (McMillan \& Schumacher, 2001). For this reason, the approach was adopted for this study to enable the participants to share their perspectives on how to address linguistic factors affecting the visualisation of word problems.

\section{Sampling}

A purposive sampling technique was used to select the participants in the study. The study involved six grade 9 mathematics teachers (from Senior phase). Of the six teachers involved in the study, one teacher was the Head of Mathematics Department who was also teaching grade 9 and supervising the other mathematics teachers. The participants had between 5 and 18 years of teaching experience. The teachers were purposefully selected to participate on the basis of their subject knowledge, expertise and experience in the field.

\section{Data Collection and Instruments}

Meetings (focus group discussions and reflection sessions) were conducted in September and October 2017 and were audio recorded. Although the home language of the teachers and learners at the school where the data were collected was Sesotho, the school used English as the medium of instruction. Three focus group discussions and three reflection sessions, each meeting lasting for approximately two hours, were conducted. The focus group discussions were used to give the teachers a platform to discuss, as a group, the linguistic factors that influenced the visualisation of word problems so as to gain an in-depth understanding of the challenges thereof. The reflection sessions, on the other hand, were conducted in order for the teachers to reflect upon their own practices and experiences, thereby highlighting and suggesting ways to enhance the visualisation of word problems. The data collection was conducted in both English and Sesotho.

\section{Details of the Proceedings of the Reflection Sessions and Focus Group Discussions}

\section{First reflection session}

After explaining to the participants what the study would entail and clarifying their role in the study, the researcher invited the participants to introduce themselves. The participants introduced themselves and reflected by giving details on how long they had been working as mathematics teachers and how much knowledge and experience they had regarding teaching mathematics, and word problems specifically. During this session, the researcher realised that the participants had varied mathematics teaching experience and knowledge of teaching word problems. The session was meant for the participants to open up and was a reflection in the sense that they got to reflect on their experiences in teaching word problems, thus indicating their affinity for or dislikes of word problems.

Listening to the participants' reflections, the researcher realised that four of the six teachers who were participating in the study were highly experienced (10 to 18 years of teaching experience) and had been successfully teaching word problems. The other two teachers indicated that they had little experience (5 years) in teaching word problems, and though they found these problems challenging, they enjoyed teaching them because they helped learners relate the content to real-life events. On the basis of discovering the variations in teaching experience and knowledge of word problems, the researcher formed two focus groups in order to focus the questions and thus elicit as much information as possible from the teachers.

\section{Second reflection session}

During the second reflection session, the researcher first had to confirm the information that she had transcribed from the audio recording. She then recapped the participants' details (i.e., their profiles) and some experiences regarding the teaching of word problems, which they had shared with her in the first reflection session. She did this in order to verify whether she had captured their information correctly. During this session, the participants reflected on how they taught word problems (i.e., explain the approaches they were using to teach word problems).

\section{Focus group discussions}

The three focus group discussions with each group were conducted to give the two groups of teachers the opportunity to discuss linguistic factors that affected the visualisation of word problems. During the first focus group discussion, the participants identified and discussed factors that affected the visualisation of word problems. The researcher facilitated the session and probed the participants to clarify their points and elicit 
more information. The second and third focus group discussions were focused on discussing solutions to address the linguistic factors that affected the visualisation of word problems.

\section{Third reflection session}

The two groups were combined for everyone to reflect on what had been discussed during the previous reflection and focus group discussion sessions. During this focus group discussion, clarification and elaboration were made regarding factors that affected the visualisation of word problems and solutions for addressing them.

\section{Data Collection Procedure}

The free attitude interview (FAI) technique can be employed to help initiate discussions in meetings (Meulenberg-Buskens, 2011), as was done in this study. The FAI technique is a data generation technique that seeks to provide the participants with a platform to talk freely as in a normal day-to-day conversation (Meulenberg-Buskens, 2011). The normal conversational nature thereof makes it easy for participants to speak freely and voluntarily engage in discussions (Tsotetsi, 2013). When the FAI technique is used, one comprehensive question is usually posed to initiate conversations (Meulenberg-Buskens, 2011). In this study, two comprehensive research questions were asked, namely:

- What are the language factors that affect the visualisation of word problems and the related challenges thereof?

- How can the challenges pertaining to the identified language factors be addressed to enhance the visualisation of word problems?

In line with the requirement of FAI (i.e., one question posed to initiate the discussion), the first question was posed during the focus group session in order to prompt discussions leading to the generation of data that reflected the language factors that affected the visualisation of word problems and the related challenges thereof. The second question was posed during the reflection session to provide the participants with an opportunity to recommend solutions to the identified challenges. Subsequent to the reflection and focus group discussions, a reflective summary was compiled to encourage the participants to think carefully about their arguments and suggestions (Mahlomaholo, 2009).

\section{Ethical Considerations}

The study was ethically cleared by the University of the Free State, and an ethical clearance letter was issued. Permission to conduct the study was obtained from the Department of Education and the principal of the school where the study was conducted. The participants in the research signed consent forms in which their right to confidentiality was emphasised and they were assured of anonymity. They were also informed that their participation was voluntary and that they would not be penalised for deciding not to proceed with participation at any stage of the research project.

\section{Data Analysis}

Thematic analysis was used to analyse the data. The technique was used to identify, analyse and interpret patterns of meaning (themes) within the qualitative data (cf. Braun \& Clarke, 2019). The technique assisted in terms of providing accessible and organised procedures for generating codes and themes from qualitative data (cf. Vaismoradi et al., 2013). The technique made it possible to identify and organise the emerging themes and sub-themes according to challenges and solutions. The following steps, suggested by Braun and Clarke (2006), were followed to perform thematic analysis: data familiarisation; generation of initial codes; searching for themes; reviewing themes; defining themes; and writeup.

\section{Trustworthiness}

Credibility is important in research; it is all about making certain that the study measures what it is envisioned to do (Maher et al., 2018). In this study, the FAI technique was employed to afford the participants the opportunity to engage in lengthy discussions. Through the open-ended questions that were asked, the participants were able to say more than they would have been able to say in a close-ended questionnaire. This technique made it possible for more clarity to be provided. The CER lens adopted in the study afforded the participants the opportunity to explain issues from different perspectives, thereby enabling the researcher to establish the deeper meaning of what they were saying. The use of compound instruments made it possible for triangulation to be performed and data to be corroborated. In order to eliminate bias by conceding the researcher's predispositions, member checking was conducted to ensure that the data were analysed and the findings interpreted in a manner that captured and portrayed the participants' ideas and opinions correctly.

It is critical to note that the themes that emerged, only applied to the context of the case study reported in this paper and might have come out differently if a similar study were to be conducted in another context. As this was a case study that sought to explore a phenomenon using a few participants in a school setting, the findings will not be generalised. However, the findings will contribute to the body of knowledge by illuminating some ways in which the visualisation of word problems can be enhanced and the language factors to be considered in successfully doing it. 


\section{FINDINGS AND DISCUSSION}

The following sections highlight the three themes that emerged and provide discussions on the analysis and interpretation of the data.

\section{Theme 1: Lack of Reading Skills}

In a focus group discussion in which the challenges pertaining to the teaching of word problems were discussed, a lack of reading skills, laziness to read and an inability to translate the language of learning and teaching to the home language were highlighted as some of the factors that affected the visualisation of word problems. The following was said:

I have noticed in many instances that our learners struggle to read, and this makes it difficult for them to visualise word problems. There is no way in which they can visualise the problems if they do not understand the word problems given to them. (Teacher 1)

The thing is, we only focus on the content that we are teaching and forget that reading plays a significant role when teaching maths. We often do not focus on reading but solving mathematical problems, that's all! [A] lack of reading skills and understanding the word problems make it difficult for learners to understand what the problem entails or requires to be solved. (Teacher 5)

... truth be told, our learners are too lazy to read the word problems, and to some extent, this is caused by us, teachers, because the word problems are also challenging for us, and also, we do not like them since they require a lot from us. We do not even make effort to come up with reading strategies to help improve the learners' understanding of the word problems and I think this is why learners in our classes have low reading skills. (Teacher 6 )

Hape hape ho thata ho bona [it is also difficult for them] to visualise the problem since batlabe basa kgone le ho transleita [they cannot translate] word problems into any of the home languages. It helps when they are able to translate word problems into their home languages because the home languages make it possible for them to make sense of the word problems. (Teacher 4)

... a word problem like this one, "Palesa built the tower that is five less higher than Thabo's. Represent this expression algebraically." A word problem like this one, even if learners can read it, if they do not have [an] understanding of mathematical language and structure, it will be difficult to represent it algebraically. (Teacher 3 )

Teacher 1 noted that many learners struggled with reading, which made it difficult for them to visualise word problems. Reading with no understanding makes it difficult for learners to make sense of word problems and to create mental pictures (visualise) of these problems; hence Teacher 1's statement, "There is no way in which they can visualise the problems if they do not understand them". According to Gomez et al. (2020), reading has an impact on the development of vocabulary, and if learners cannot read fluently, their vocabulary skills can be negatively affected, making it difficult for them to solve word problems.

What seems to contribute to learners' lack of reading skills, according to Teacher 5 , is that no substantial effort seems to be made by teachers in terms of teaching learners how to read. Mathematics teachers seem to avoid the task of teaching learners how to read; however, mathematics, as a language (though not a natural one), requires a lot of reading and understanding in order for learners to master it. Mathematics teachers seem to give the impression that mathematics is only about solving problems (involving numbers); thus, they place less emphasis on other linguistic factors that also play a significant role in solving word problems, such as reading and comprehension. According to Teacher 5, a lack of reading skills makes it difficult for learners to understand word problems. This, in turn, makes it difficult for meaning making to be established, which, subsequently, hampers the visualisation process. In agreement, Musdizal (2019) regards a lack of reading skills as a factor that could potentially hamper the understanding and visualisation of word problems and therefore suggests the need to devise reading strategies that promote effective visualisation of word problems.

According to Teacher 6, part of the reason why learners lack reading skills is because they are lazy to read, and this is that they are not often engaged in reading exercises by their teachers. Teachers seem not to be keen to teach word problems and even dislike them because they too find word problems challenging and demanding. This is the case because word problems require not only mathematical knowledge in terms of solving problems but also other skills, such as reading skills, vocabulary knowledge and mathematical language, all of which contribute to successful word problem solving; hence the statement "they require a lot from us". The fact that efforts are not made by teachers to devise stimulating reading strategies to help improve learners' reading skills and understanding of word problems contributes to learners' poor reading abilities and laziness in solving these problems.

On the other hand, Teacher 4 raised another crucial issue regarding the lack of reading skills. The teacher indicated that visualising and solving word problems are not possible if learners are unable to translate what they are reading in the language of instruction into their home language (and vice versa) in order to try and make sense of the word problem. Being able to use their home language to assist in making sense of a word problem when reading is an essential ingredient of successful word problem solving because learners process thoughts 
more easily in their home language (Clarkson, 2007), which subsequently help facilitate semantic processes (Setati, 2008). However, if learners do not have reading skills and are unable to switch between their home language and the language of learning and teaching, especially to use the home language to help them make sense of a word problem, it will be difficult to visualise and solve the problem.

According to Teacher 3 , the reading of word problems not only requires learners to know the words written so that they can ultimately visualise and solve the problem, but also requires them to have knowledge of mathematical language and structure. However, it seems that they do not have such knowledge, deducing from the example that the teacher provided. According to the example provided by Teacher 3 , especially looking at the solution provided by many learners in the class in terms of converting the word problem and representing it algebraically, many learners seemed to lack knowledge of mathematical language and structure, which impeded understanding of the problem and visualisation while reading. Hence the incorrect representation of the word problem after being converted into an algebraic equation: $p=5-t$ (instead of $p=t-5)$.

\section{Theme 2: Lack of Understanding Mathematical Language and Structure}

Lack of understanding mathematical language and structure was highlighted as another factor that affected the visualisation of word problems. The teachers reflected as follows:

... learners who do not understand the mathematical language and structure are unable to visualise or create the correct picture of the problem in their heads, and you will see this when they eventually solve these problems by not being able to represent the problem on paper. (Teacher 2)

... the issue of mathematical language and structure is important because some of the mathematical sentences (word problems) when read differ from when they are to be represented algebraically. So, failure to master the mathematical language and structure in my view can potentially hinder visualisation of word problems. (Teacher 3)

I remember asking the learners to solve and represent the expression "three is at most $x$ plus five on the number line". Most of them got the answer wrong. I thought it was an easy question which they could easily represent algebraically and solve, but I realised they did not understand the mathematical language and structure involved and thus failed to make a representation of the problem and to solve it. Some, because of the expression "at most", they represented the whole expression algebraically as $3 \geq x+5$. (Teacher 6)

The participants recognised lack of understanding mathematical language and structure amongst their learners and perceived it as a hindering factor towards visualising and solving word problems. Teacher 2 highlighted that learners who do not comprehend mathematical language and structure struggle to form mental pictures of the problems and that this is often made evident by their inability to "represent the problem on paper". Teacher 3 added that "some of the mathematical sentences (word problems) when read differ from when they are to be represented algebraically" and thus lack of understanding mathematical language and structure can affect visualisation and word problem solving.

Teacher 6 also acknowledged lack of understanding mathematical language and structure as one of the factors that affect visualisation and word problem solving with the aid of an example. According to Teacher 6 most learners could not be able to translate/convert correctly the given word problem expression "three is at most $x$ plus five" into an equivalent algebraic expression and to subsequently represent it on the number line. The teacher attributed this to lack of understanding the key term "at most" (contained in the given word expression) which they subsequently symbolically incorrectly represented as $\geq$ (which refers to greater or equal to) thus representing the whole word problem algebraically as 3 $\geq x+5$ instead of $3 \leq x+5$.

\section{Theme 3: Ambiguities Caused by Polysemous Words}

Mojela (1991) refers to polysemy as a case wherein one word may have a set of more than one different but associated meanings. According to Mamolo (2010) a polysemous word is a word which has two or more different, but related, meanings which its intended meaning can be determined by the context in which it is used. Reynders (2012) avows that polysemous words may cause translation ambiguities and also impede the learners' understanding, which is why teachers need to be mindful of these words. According to Farrel (1990), and Haglund et al. (2014) the challenge that is often posed by the use of polysemous words is that certain words in mathematics share ambiguous meanings with their everyday meanings and this often causes confusion. Therefore, there is a need to pay attention to the use of polysemous words in order to avoid confusion which may arise and impede learning. The issue of polysemy was also highlighted as a possible cause of ambiguity, which might affect the visualisation of word problems during the focus group discussion. The participants commented as follows: 
Sometimes the words that we use have different meanings which may cause learners not to understand and visualise the word problems. (Teacher 1 )

...a word such as "product" which can be used in commerce can be confusing if not contextualised and clarified to learners in a maths class to avoid a situation whereby learners become lost or misinterpret the question and ultimately get the wrong answer. It is important to address this because sometimes this term can even cause the word problem to be unclear. (Teacher3)

You see a term such as "opposite" when we use it on daily basis, its meaning can assist in maths especially when dealing with ratios in trigonometry. For example, Tangent is opposite over adjacent right! However, that cannot always be the case because its definition is different when dealing with geometry and analytical geometry. (Teacher 5)

The participants recognised the ambiguity caused by the use of words which have different meanings (i.e., polysemous words) when used in different contexts as another hindering factor that causes learners to be unable to visualise and solve the word problems. Teacher 1 highlighted confusion that is caused by the words with multiple meanings, thus hampering understanding and making it difficult for learners to solve the word problems. According to Teacher 3 mathematical words which have multiple meanings need to be contextualised and clarified in order to avoid a situation where learners become lost or misinterpret the question and thus obtain an incorrect answer. In line with this, the teacher used the key term "product" as an example to show how this term can confuse learners and also can sometimes cause the word problem to be vague. The participants' opinions regarding the polysemous words which could sometimes be the possible cause of ambiguity is also supported by Reynders (2012) who claims that polysemous words may cause translation ambiguities and also cause learners not to understand clearly what the mathematical problems require them to do.

Teacher 5 on the other hand brought another interesting perspective in the discussion around ambiguity that is caused by polysemous words, indicating through the example she made that such words could cause confusion also within the different mathematical topics that use a similar term. To indicate how a term with different meanings in different mathematical topics could cause confusion, Teacher 5 made an example regarding the term "Tangent" which is used in different mathematical topics with different meanings assigned to it. For instance, in Trigonometry where focus is placed on ratios (Sine, Cosine and Tangent); Tangent is denoted through the right-angled triangle sides as, $\frac{\text { opposite side }}{\text { adjecent }}$. However, in geometry where focus is on theorems, particularly when dealing with geometry of the circle, tangent refers to a line the touches the circle at one point and is perpendicular to the radius. In analytical geometry, on the other hand, Tangent refers to a similar meaning as implied in geometry, however, in this context it is calculated as "change in y over change in $x^{\prime}$, which is algebraically represented as $\left(\frac{? y}{? x}\right) / \frac{y 2-y 1}{x 2-x 1}$. If learners in this instance only know the Trigonometry meaning of a term tangent and do not know the meaning(s) of it in geometry/analytical geometry, then such a limited knowledge may cause vagueness and impede learning of the geometric related problems.

\section{Theme 4: Ambiguities Caused by Code Switching}

Code-switching is a communicative practice that involves shifting which occurs between multiple languages concurrently or interchangeably within one conversation (Azlan \& Narasuman, 2013). Salehmohamed and Rowland (2014) regard it as an essential support for learning in mathematics classrooms. According to Kim (2015) code-switching as a communicative practice, assists in promoting effective learning particularly in situations wherein English is used as a second language. Although code-switching provides benefits that include scaffolding learning to improve learners' performance in mathematics (Setati, 1998), Maluleka (2019) avows that a prevalent perception still exists that code-switching distracts the efficient running of lessons and derails learners from acquiring proficiency in English, which is the language of learning and teaching. In line with this, code-switching was also identified as a possible cause of ambiguity during a focus group discussion. The teachers commented as follows:

... sometimes we code switch and use the home languages, only to find that what we translate in English is not the same as when we explain that using our home languages. (Teacher 4)

Although I agree that code switching helps especially when there are learners who struggle to understand the language of instruction, I also feel like at times it creates problems because translating words in Sesotho for instance into English can be difficult and can also result in translating words incorrectly. Such mistranslations in between can cause elements of ambiguity. (Teacher 2)

I remember in one of my sessions with the learners asking the question "what is the difference between eighteen and nine?. but I asked the question code switching and I remember saying... "ke eng (ET: what is?) the difference between eighteen and nine?" and then immediately asking the same question but then saying "ke bokae (ET: how much is?) the difference between eighteen and nine?"... This was confusing because we ended up having a discussion which made 
me realised that the two phrases "ke eng? (ET: what is?) and ke bo kae? (ET: how much?)" were creating confusion. The question which I asked ended up being ambiguous because of using these two phrases which learners understood and interpreted differently. (Teacher 3)

...though the phrase "ke eng (ET: what is) the difference?" was incorrect in an instance where the learners used a comparison instead of subtracting one number from the other one the same meaning could still be applicable and result in the attainment of the correct answer in another topic. For example, ke eng difference between square and rhombus? (Teacher 6)

Teacher 4 mentioned code switching as one of the factors that hampered visualisation and word problem solving and explained that this occurs because "what we translate in English is often not the same as when we explain that using our home languages". In agreement with Teacher 4, Teacher 2 admitted that although code switching is useful, particularly when teaching learners who are struggling with the language of instruction, it has the potential to hinder the learning process. According to Teacher 2, translating words in Sesotho into English and vice versa can be difficult as this can lead to incorrect translations which could in turn, cause ambiguity. This is because words in Sesotho when translated into English may not produce similar meanings.

Teacher 3 provided an example of the question that she asked learners whilst using "code switch" language practice. She wanted learners to give an answer pertaining to the question "what is the difference between eighteen and nine?" since they were dealing with the concept of subtraction. However, the two phrases that she used in Sesotho in the two sentences that she used created confusion which she identified when engaging with learners in discussions. The learners who understood the first phrase, i.e., "ke eng (ET: what is?) the difference between eighteen and nine? Compared the two numbers (18 and 9). Some said 18 is bigger and double the number 9; others indicated that 9 is a one digit number whilst others indicated that 18 consists of two digits. The interpretation that led to these answers was prompted by the phrase "ke eng? (meaning what) which then made them (learners) think the teacher was looking for answers that speak to "the difference" in the sense of highlighting features that make the two numbers differ. On the other hand, the learners who understood the second phrase "ke bokae (ET: how much) is the difference between eighteen and nine?" subtracted nine from eighteen and obtained nine as an answer. Their interpretation was guided by the phrase "ke bokae?" (meaning how much?), which made them think that the teacher was looking for the result of subtracting one number from another one. These are the learners who understood the context in which the term difference was used (subtraction concept) and thus provided the correct answer.

Teacher 6 indicated that even though the code switching of the phrase "ke eng (ET: What is) the difference?" had resulted in incorrect interpretation of the question by the first group of the learners as highlighted by Teacher 3 , the meaning of the same "code switched" phrase would be correct when used in another topic in mathematics. The teacher thus made an example to indicate that the comparison meaning attached to the phrase which was incorrect when dealing with subtraction concept, would be correct when dealing with shapes and properties in geometry where the goal is to contrast the shapes.

The teachers' extracts therefore signify the need to carefully use code switching in order not to create confusion and to cause ambiguity of the word problems. The ambiguity should therefore be avoided as it has the potential to impede learning and to make it difficult for word problems to be visualised and solved.

\section{Solutions Identified to Address Language Factors that Influence the Visualisation of Word Problems}

The reflection sessions that were conducted provided the teachers with opportunities to discuss and suggest or recommend possible solutions to the identified challenges. They made suggestions based on their teaching experiences, indicating how they attempted to overcome or address the language factors that affected the visualisation of word problems.

\section{Improving Reading Skills}

Evidence shows that reading skills play a significant role in terms of promoting visualisation (Moriyanti et al., 2019). In line with this, Mulligan (2011) emphasises the need for teaching methods that optimise reading skills in order to enhance the visualisation of word problems.

As indicated in Theme 1, a lack of reading skills may have an impact on the visualisation of word problems. Therefore, an attempt at resolving this issue in an endeavour to improve the visualisation of word problems is necessary. In line with this, some strategies were suggested by the participants to improve learners' reading skills. The following suggestions were made:

Learners need to be taught how to read. They also have to be frequently engaged in word problem solving so that they can learn mathematical language. It will [then] be easy for them to visualise the word problems. (Teacher 2)

... to improve reading skills takes a lot of time, but it has to be done. I try to give my learners a platform to read and discuss at the same time. It helps because I am able to pick up the misconceptions quickly as they discuss what they are reading. (Teacher 5) 
Colleagues, reading goes with thinking and that is what we need to train our learners to do; that is, to read and think at the same time. Let us have a look at the following problem ... [showing the problem from a workbook]:

Question 1:
Mr Ndlovu sold twice as much apples in the afternoon
than in the morning. If he sold 300 kilograms of apples
that day, how many kilograms did he sell in the
morning and how many in the afternoon?

You see! ... a problem like this one requires learners to read and think at the same time, which is what we need to teach our learners. This is the kind of a problem that learners have to read, think about what they are reading, understand the context and understand what they are reading so that they can be able [sic] to translate that into maths expressions to be able to solve it. (Teacher 3)

...What also works is to ask them to read the problem and highlight the keywords, which I think are the words that will help them know how to solve the problem and also highlight the words that they do not know. (Teacher 4)

The participants alluded to the significance of teaching learners how to read as part of improving their reading skills and visualisation of word problems. According to Teacher 2, teaching learners how to read and also frequently engaging them in word problem solving is vital for them to learn mathematical language. This in turn enables the learners to visualise the word problems. Teacher 5 also acknowledged the significance of engaging learners in reading exercises, but cautioned that the activity demands a lot of time to be invested in order to improve reading skills. Teacher 5 noted that she creates reading and discussion platforms for learners in class and explained that such platforms assist her to identify the learner misconceptions that may cause them not to understand and visualise the word problems.

On the other hand, Teacher 3 emphasised the need for teachers to train learners to read and think simultaneously. According to the teacher, this strategy (i.e., reading and thinking at the same time) is essential to assist learners to create mental pictures of what they are reading about. Teacher 3 also emphasised the significance of making learners understand the context when reading word problems. The mathematics word problem that she alluded to, as an example, requires learners to think not only about what they are reading and the context thereof, but also about the mathematical vocabulary that is used in order to be able to make sense of it. This is important, according to Teacher 3 , because reading with understanding, thinking about what one is reading and identifying mathematical keywords, make it possible for learners to visualise and solve the word problem by translating the word problems into mathematical expressions (composed of variables and numbers) that are easy to be solved, as shown below:

In this case, the translation of the word problem into mathematical equation (e.g., algebraic equation) will be as follows:

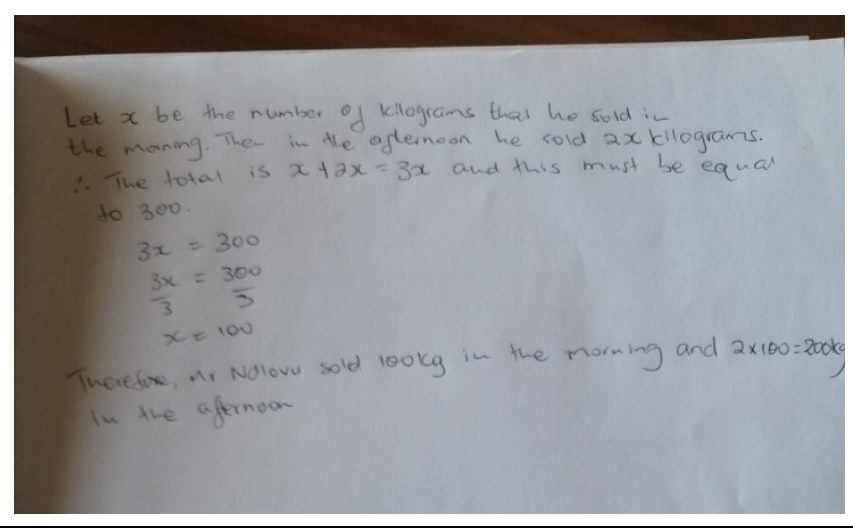

Teacher 4 on the other hand, suggested the idea of highlighting keywords while reading because these are the words that will eventually enable learners to visualise and solve the problems. Also of vital importance is for learners to highlight words they do not know when reading a word problem. Learning more about these unfamiliar words will help improve their reading skills and understanding, thus also making it possible for learners to visualise the word problem.

\section{Enhancing Word Problem Visualisation Through Explicit Teaching of Mathematical Language and Vocabulary}

Evidence shows that the teaching of mathematical vocabulary contributes towards promoting the visualisation and effective learning of word problems (Franz, 2009). Vula and Kurshumlia (2015) maintain that learners will continue to struggle to solve word problems if they cannot visualise the problems and also lack the grasp and knowledge of the essential mathematical vocabulary. Therefore, Ní Ríordáin et al. (2015) encourage the use of strategies that develop mathematical vocabulary and register acquisition to promote visualisation. In line with this, some strategies were suggested by the participants to address learners' lack of mathematical vocabulary in an attempt to enhance the visualisation of word problems:

... an amount of time needs to be devoted to the teaching of mathematical vocabulary. Learners often rely on these terms to understand and figure out what steps to be [sic] taken to solve the problems. (Teacher 3)

... mathematical vocabulary is important because it helps learners to make text connections in order to make sense of the word problems and to contextualise them, and this helps to visualise the problems. (Teacher 1) 
I always try to address the terms that are used in mathematics as well as in other contexts by making sure that I differentiate the meanings. This helps to eliminate confusion that might arise. (Teacher 5)

The teaching of mathematical vocabulary was deemed significant to improve visualisation of the word problems. According to Teacher 3 the grasp of mathematical vocabulary is important because "learners often rely on these terms to understand and figure out what steps to be taken to solve the problems". Teacher 1 also stressed the significance of mathematical vocabulary by indicating that it helps learners to make text connections so to make sense of the word problems and to contextualise them. Teacher 5 added by highlighting the importance of differentiating the meanings of the key terms that are used in mathematics as well as in other contexts when teaching mathematical vocabulary in order to avoid confusion which may subsequently result in learners being unable to visualise the word problems.

Another suggestion in terms of eliminating confusion was made by Teacher 6 . The participant commented as follows:

\begin{abstract}
... when I teach word problems, I make sure that I address not only the vocab but also the mathematical language and structure. You see, the expressions such as ... "three is at most $x$ plus five" ... "three is less than five less a number"..."less a number" can make it difficult for learners to visualise and solve word problems, especially when learners do not know and understand these expressions. Yes, we are maths teachers, but I think we have the responsibility to address language when we teach as well. (Teacher 6)
\end{abstract}

Teacher 6 highlighted the need for paying attention to mathematical language when teaching word problems because knowledge of mathematical language facilitates understanding, and this enables learners to visualise the word problems. According to Teacher 6, an understanding of mathematical expressions such as "three is at most $x$ plus five" ... "three is less than five less a number"... "less a number" is crucial because these expressions help learners make sense of the given word problems and also inform multiple representations, either in graphic or algebraic format, and facilitate smooth problem solving. The teacher also raised an important issue, that even though they teach mathematics content, they also have the responsibility to address language issues.

Further suggestions made by the participants are as follows:

We need to allow the learners to give responses in their home languages. However, to ensure that they learn the correct mathematical language, what we could do as teachers is to reiterate what they are saying using mathematical language. (Teacher 1)
... the teacher needs to make sure that he or she understands what the learner is saying in order to provide the correct mathematical language. (Teacher 5)

The use of home languages was also endorsed by Teachers 1 and 5 as a strategy that could be used to reinforce the understanding of word problems. Understanding a word problem is essential to be able to visualise the word problem (Teahen, 2015). Thus, in order to improve learners' knowledge of mathematical language and structure, Teacher 1 indicated that it was important for learners to be given opportunities to give responses in their home language. The participant, however, noted that when this is done, teachers should revoice or repeat or reformulate the learners' responses using the correct mathematical language and structure (i.e., restate the learners' responses using the appropriate mathematical language).

Teacher 5 added that in order for teachers to provide the correct mathematical language and structure, they have to understand what the learners are saying so that they can reiterate the learners' responses using the appropriate and correct mathematical language and structure. Both Ferguson (2003), and Halai and Karuku (2013) support the use of home languages as a resource for supporting learners with limited proficiency in the language of learning and teaching and for reformulating learners' sentences or responses. The use of home languages is therefore important to reinforce understanding, which is key to visualising the word problems.

\section{Eliminating Ambiguities to Enhance the Visualisation of Mathematics Word Problems}

Evidence shows that the elimination of ambiguities can significantly improve the visualisation of word problems (Kaplan et al., 2014). Kaplan et al. (2014) assert that making learners aware of ambiguities enables them to distinguish between colloquial meanings and technical meanings. The participants also seemed to be in agreement with this notion and stressed the need to eliminate ambiguities when teaching word problems to improve visualisation. They commented as follows:

We need to teach learners about the different forms of mathematical expressions and how they apply in real life as opposed to how they apply in mathematics classrooms. This will eliminate the ambiguities. (Teacher 2)

I sometimes find probing helpful. It helps me to establish the things that make learners fail to work out the problems given to them and also some elements that cause word problems to be ambiguous. (Teacher 1)

It helps to provide word problems and the pictures or diagrams alongside like [showing a word problem and 


\section{Measurements}

\section{REVISION EXCERCISE}

\begin{abstract}
One of the ends of a cylindrical pencil is to be sharpened to produce a perfect cone. The length of the pencil is not to be
\end{abstract} lost. The diameter of the pencil is $1 \mathrm{~cm}$ and the length of the cone is $2 \mathrm{~cm}$. Calculate the volume of the shavings removed.

Figure 1. Example of a word problem with a picture alongside

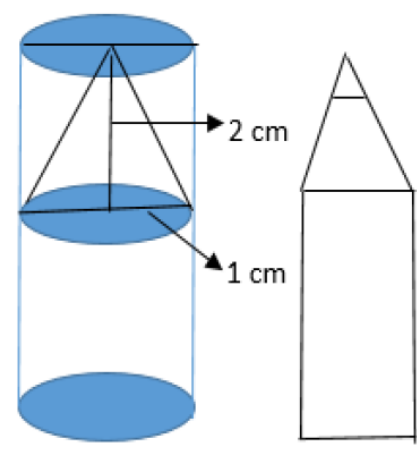

diagram (see Figure 1)]... This helps to eliminate the confusion and also helps learners focus and recognise the implied context. (Teacher 6)

According to Teacher 2, teachers have to provide learners with opportunities to familiarise themselves with different mathematical forms of expressions by teaching these learners how these forms of expressions are used to communicate mathematical ideas as opposed to how they are used ordinarily. Teacher 2 therefore drew attention to the careful use of mathematical expressions, especially when those expressions are used in other contexts in order to avoid confusion. Teacher 1 mentioned probing as a useful practice for identifying elements of ambiguity that might cause confusion and hamper the visualisation of word problems. According to the teacher, probing enables teachers to determine which words the learners find confusing or use incorrectly, which make it difficult for them to understand and visualise word problems. Teacher 6 , on the other hand, suggested the use of pictures alongside word problems as another form of representation to guide the reading and understanding of word problems. According to the participant, pictorial representations should be used to represent the situation as depicted in a word problem text. This will help learners focus, recognise the implied context and thus think about the appropriate concepts and operations to be used to solve the given word problems.

\section{Linguistic-Focused Approach to Enhance the Visualisation of Word Problems}

This section explains how the theories or conceptual frameworks outlined in the literature review section have been advanced by the findings of the current study. The study reported in this paper highlights the new linguistic-focused approach to enhance the visualisation of mathematics word problems resulting from the findings. The sections indicate how this new framework improves the highlighted frameworks in the literature review section.
Previous research shows more emphasis placed on the use of concrete representations in the form of physical objects and the diagrams in the form of visual images as the tools for visualisation (Cease-Cook, 2013; Gallenstein, 2005). The concrete representations have been found to "have the potential to offer memorable imagery that can act as a touchstone for teachers and learners in building and discussing abstract concepts"(Gerofsky, 2009, p. 36). Drawing the pictorial representations was also found to be a useful strategy for scaffolding visualisation (Bakar, 2017). Role play as a strategy that is informed by realistic mathematical modelling was also found to be useful in terms of exposing learners to real-life situations in an endeavour to help them model mathematical concepts out of such situations (Gao et al., 2009). This was found to also be a good strategy for enhancing visualisation by bringing the participants as close as possible to reality (Sogunro, 2004). Although research on visualisation has shown its positive effects on learning through the use of representations and role plays, there is limited research that focuses on linguistic aspects that affect visualisation of mathematics word problems. In line with this, the contribution which this study makes is to propose a linguistic-focused approach to advance the existing research on visualisation, which does not seem to be focusing much on these important linguistic aspects.

Grade 9 serves as a transitional grade for learners to move to further education training (FET) and also serves as a foundation for grade 12 mathematics. However, the findings of this study revealed that the teaching of mathematics in this grade is often challenging for most teachers because the English language is not well developed as yet in learners. Based on this therefore, the findings revealed that it is important to develop a context in which the teaching of grade 9 mathematics does not only focus on procedural learning but also carried out in a manner that places focus on linguistic aspects. An extensive literature searching shows that there are not many studies that are similar to the context 
of the current study, which highlight the linguistic aspects that affect visualisation of mathematics word problems in grade 9. Although the teachers' perspectives in this article confirm the research undertaken globally, this paper also provides some perceptions that are not always equally emphasised by other scholars. For instance, literature indicates that lack of reading skills impedes learning, which is what the current study also revealed. However, in the current study, some of the root causes of lack of reading skills were identified and they included; teachers' practices which only focus on mechanical ways of solving the problems without focusing on linguistic aspects involved to reinforce understanding and to improve visualisation. The root causes also included teachers' tendency of not incooperating the reading strategies into their lessons to teach learners how to read and thereby ignoring the fact that mathematics is a language (though not a natural one) which also requires learners to be taught how to read. The tendency thus led to laziness that was exhibited by the learners when it came to solving word problems. Based on this therefore the current study proposes transformational planning of teaching, which takes into account the linguistic aspects (reading and comprehension) in an endeavour to enhance visualisation of word problems. This means that mathematics teachers need to regard themselves not only as mathematics content teachers but also as the linguistic facilitators, who not only teach mathematics as a numerical content but also as a language, which it is. Accordingly, to address lack of reading skills in an endeavour to improve visualisation of word problems, the findings of the study suggest teachers should:

o devise the productive reading strategies and incooperate them into the teaching of word problems.

o teach learners how to translate word problems into mathematical expressions / equations that are easy to solve.

- use the learners' home languages as resources to aid understanding of the word problems, which are written in the language of learning and teaching (LoLT - English).

$\circ$ build strategies for vocabulary learning to improve learners' reading skills.

- create reading opportunities in class and devote time to teach learners how to read.

- frequently engage learners in reading exercises concerning word problems.

o train learners how to read and think simultaneously, when solving the word problems.

o ensure that learners read and think about what they are reading whilst identifying the mathematical keywords (i.e., the words that are found in word problem sentences whose knowledge of, makes it possible for word problems to be solved)

o provide learners with a platform to read and discuss what they are reading simultaneously. (This will assist in terms of swift identification of the misconceptions which learners might have).

- group learners so that they can read and work together on the given word problems. This will enable learners to share different perspectives amongst themselves and also be able to help one another to make sense of the given word problems.

Literature shows some perceptions regarding code switching as a communicative practice that is used to teach mathematics learners especially in settings wherein English is offered as a second language (Kim, 2015). Although code switching provides benefits that include scaffolding learning to improve learners' performance in mathematics in such settings (Setati, 1998), Maluleka (2019) avows that code-switching has the potential to distract the smooth running of lessons and derail learners from acquiring proficiency in English, which is the language of learning and teaching. Similar perceptions were also confirmed in the current study. However, the study revealed that code switching can cause what is termed, "translation ambiguity" which is a result of translating words in home-language (for example, Sesotho) into the language of learning and teaching namely, English. The study also revealed that code switching needs to be used carefully, so that learners could be able to acquire knowledge of the language of instruction and learn mathematical content through it whilst their home languages are used to support comprehension of the word problems. This therefore means that teachers should pay attention to issues pertaining to code switching in order to use it (code switching) profitably and efficiently as a "resource" for teaching and learning to reinforce understanding of the word problems. Furthermore, the study cautioned teachers to be mindful of the manner in which they use words when code switching to avoid causing "semantic ambiguity", which has the potential to make learners understand the concepts in "more than one way" thus impeding learning and visualisation of the word problems.

Reynders (2012) on the other hand, avows that polysemous words may cause translation ambiguities and also impede the learners' understanding of word problems, which is why teachers need to be mindful of these words when they teach word problems. According to Farrel (1990), and Haglund et al. (2014) the challenge that is often posed by the use of polysemous words is that certain words in mathematics share ambiguous meanings with their everyday meanings and this often causes confusion. Similar perceptions were shared by the participants in this study. However, the study 
suggests the need to distinguish the mathematical expressions which carry different meanings, when applied in other context as opposed to when these words are applied in mathematics to avoid confusion. The study also recommends that learners should be taught about these words (polysemous words).

According to Kurshumlia (2015) learners continue to struggle to solve word problems because they cannot visualise the problems and also lack the comprehension and knowledge of the essential mathematical vocabulary. Ní Ríordáin et al. (2015) thus embolden the use of strategies that develop mathematical vocabulary and register acquisition to promote visualisation. Similar perceptions were shared in the study. The study, however, highlighted some strategies which teachers should employ to address lack of mathematical language and structure. The strategies include:

- making learners aware of the fact that the "left-toright, word-for-word" translation of the word problems does not always produce the correct mathematical solutions.

- making learners aware of the fact that word problem solving requires a holistic understanding of the given word problems in order for the correct solutions to be attained and for the correct representations to be produced.

$\circ$ using strategies that develop mathematical vocabulary and register acquisition.

o using probing technique in order to fully understand what the learners are saying in their home languages when they give responses so that they (teachers) can ultimately reiterate the learners' statements using the appropriate and correct mathematical language and structure.

o striving to advance their (teachers) mathematical content knowledge (MCK) so that they can be able to correctly reiterate the learners' responses in their home languages by using the correct mathematical language and structure.

The linguistic-focused approach that is highlighted in this study promotes teaching, which takes into account the linguistic aspects that affect visualisation of mathematics word problems. The approach shows the role which language plays in terms of conceptualising, analysing, interpreting, decoding and making sense of the word problems in order to visualise and successfully solve the word problems. The approach espouses a "paradigm shift" in terms of approaching the teaching and learning of mathematics word problems. This means that the teaching of mathematics word problems should be planned and carried out in a manner that places emphasis not only on the content and the procedures to be followed when solving the problems but also on the linguistic aspects that might affect visualisation of the word problems. The approach thus seeks teachers to incooperate strategies that help develop the learners' linguistic abilities to be able to visualise and ultimately develop mastery of the word problems. Furthermore, the approach requires the mathematics teachers to be regarded as both the mathematics content and language facilitators. This therefore means that the task of teaching mathematics word problems should not only involve the conversion of word problems into mathematical expressions and equations that are easy to solve but also involve paying attention to the development of learners' linguistic abilities to enable them to successfully solve these problems.

\section{Limitations of the Study and Recommendations for Future Studies}

The study reported on the teachers' perspectives of the linguistic factors that affect visualisation of the word problems. Through the study, a linguistic-focused approach which encompasses guidelines for addressing the linguistic factors that affect visualisation of the word problems was developed. Although the study has outlined the linguistic factors that affect visualisation of the word problems and also provided the solutions to the challenges thereof, the study could not provide a strong link between linguistic factors and "Visualisation of Mathematics Word Problems." This is because the study only focused on the teachers' perspectives and did not include student data. Since the students were not included in the study, the study therefore could not provide a clearer evidence on how teachers' language affect their (learners) visualisation of the word problems. Based on this therefore, I recommend that further studies be conducted with the inclusion of the students so that their data could be collected to indicate how teachers' language use, affect visualisation and consequently, the understanding of the word problems.

Another limitation is that the study was conducted in one school and therefore, the findings cannot be generalised as they might have come out differently if a similar study was conducted in a different context. However, in contexts that are similar to that of this study, the findings of the current study would be applicable. Therefore, further studies have to be conducted in various contexts in order for more issues to be discovered and for more strategies to be identified to address the linguistic factors that affect the visualisation of word problems.

\section{CONCLUSION}

The present study addresses a very important issue in mathematics, namely visualisation, which plays a vital role in the teaching and learning of word problems. A lack of reading skills, understanding mathematical language and structure, and ambiguities were found to be some of the linguistic factors that affect the visualisation of word problems. The study thus revealed that careful planning of the teaching of word problems 
should be done by considering these factors in an attempt to enhance visualisation. Moreover, the study revealed that the task of a mathematics teacher should not only be to teach mathematical content but also to pay attention to the linguistic aspects involved. This means that mathematics teachers should play a double role by being facilitators of both mathematics and linguistic content.

From the findings of the study, the conclusion can be made that the teaching of word problems is intricate. This is because word problems, on the part of the teacher, demand not only knowledge of the mathematics subject content but also awareness, a deeper understanding of and proficiency in mathematical language to be able to deal with the linguistic factors that may impede the visualisation of word problems. Substantive efforts thus have to be made in terms of teaching word problems.

In order to devise productive teaching strategies that will enhance the visualisation of word problems, the study revealed the need for teachers as practitioners to work jointly, thus sharing ideas to improve learning. Adopting a CER lens is, therefore, pertinent in terms of fulfilling this mandate, since it promotes the notion of creating platforms for experiences to be shared from multiple perspectives. This lens also requires the solutions to be provided by the people who experience the challenge (in this context, mathematics teachers). Such a lens thus plays a critical role in teaching and learning by doing the following: (i) creating space for sharing knowledge (i.e., teachers coming together to share knowledge and ideas on how to improve the visualisation of word problems); (ii) creating space for teachers to empower themselves through intense engagements (i.e., teachers learning from one another's experiences of teaching word problems); and (iii) creating a space for productive and meaningful solutions to be formulated to inform the desired change (i.e., teachers identifying and suggesting solutions to address the factors that impede the visualisation of word problems). The teachers who participated in this study worked together, and through intense sharing moments during the focus group discussions and reflection sessions, they were able to learn from one another's experiences. Consequently, they became more enlightened, and this contributed to their perspectives on the role of visualisation in the teaching and learning of mathematics. The CER lens adopted in the study thus made it possible for some guidelines to be generated in terms of addressing linguistic factors that influence the visualisation of word problems.

It should be noted though, that the study dealt with qualitative data (teachers' perspectives, i.e., their views/opinions/beliefs), which potentially also represent their (teachers) world views and teaching philosophies. Although such views cannot be regarded as hard evidence, they can uncover valuable pointers that may serve as hypotheses in more structured studies.

Funding: The author acknowledges the support of the National Research Foundation (NRF) in the completion of this study.

Declaration of interest: No conflict of interest is declared by the author.

\section{REFERENCES}

Ahmad, A., Tarmizi, R. A., \& Nawawi, M. (2010). Visual representations in mathematical word problem solving among form four students in Malacca. Procedia - Social and Behavioral Sciences, 8, 356-361. https:// doi.org/10.1016/j.sbspro.2010.12.050

Algozzine, B., \& Douville, P. (2004). Use mental imagery across the curriculum. Preventing School Failure: Alternative Education for Children and Youth, 49(1), 36-39. https:/ / doi.org/10.3200/PSFL.49.1.36

Aspers, P., \& Corte, U. (2019). What is qualitative in qualitative research. Qualitative Sociology, 42(2), 139-160. https://doi.org/10.1007/s11133-0199413-7

Bakar, K. A. (2017). Young children's representations of addition in problem solving. Creative Education, 8(14), 22-32. https://doi.org/10.4236/ce.2017. 814153

Boonen, A. J., Reed, H. C., Schoonenboom, J., \& Jolles, J. (2016). It's not a math lesson--We're learning to draw! Teachers' use of visual representations in instructing word problem solving in sixth grade of elementary school. Frontline Learning Research, 4(5), 55-82. https:/ / doi.org/10.14786/flr.v4i5.245

Boulton-Lewis, G. M. (1998). Children's strategy use and interpretations of mathematical representations. The Journal of Mathematical Behavior, 17(2), 219-237. https:/ / doi.org/10.1016/S0364-0213(99)80060-3

Braun, V., \& Clarke, V. (2006). Using thematic analysis in psychology. Qualitative Research in Psychology, 3(2), 77-101.

https:/ / doi.org/10.1191/1478088706qp063oa

Braun, V., \& Clarke, V. (2019). Reflecting on reflexive thematic analysis. Qualitative Research in Sport, Exercise and Health, 11(4), 589-597. https:/ / doi.org/10.1080/2159676X.2019.1628806

Carden, J., \& Cline, T. (2015). Problem solving in mathematics: The significance of visualisation and related working memory. Educational Psychology in Practice, 31(3), 235-246. https://doi.org/10.1080/ 02667363.2015 .1051660

Cease-Cook, J. J. (2013). The effects of concreterepresentational-abstract sequence of instruction on solving equations using inverse operations with high school students with mild intellectual disability (Doctoral dissertation). University of North Carolina at Charlotte. 
Charles, R. (2011). Solving word problems: Developing quantitative reasoning. New York, NY: Pearson.

Creswell, J. W. (2009). Mapping the field of mixed methods research. https: / / doi.org/10.1177/1558689808330883

De Koning, B. B., \& Van der Schoot, M. (2013). Becoming part of the story! Refueling the interest in visualization strategies for reading comprehension. Educational Psychology Review, 25(2), 261-287. https: / / doi.org/10.1007/s10648-013-9222-6

Demirsoy, E. (2020). Challenges faced by newly arrived students with low English proficiency and their English teachers in Sweden: Three teachers' accounts (Doctoral dissertation). University West.

Denzin, N. K., \& Lincoln, Y. S. (2005). Introduction: The discipline and practice of qualitative research. In $\mathrm{N}$. K. Denzin, \& Y. S. Lincoln (Eds.), The Sage handbook of qualitative research (3rd ed., pp. 1-28). Sage.

Ding, M., \& Li, X. (2014). Transition from concrete to abstract representations: The distributive property in a Chinese textbook series. Educational Studies in Mathematics, 87(1), 103-121. https://doi.org/ $10.1007 /$ s10649-014-9558-y

Dold, C. J., \& Chapman, R. A. (2012). Hearing a voice: Results of a participatory action research study. Journal of Child and Family Studies, 21(3), 512-519. https: / / doi.org/10.1007/s10826-011-9505-9

Essien, A. A. (2013). Preparing pre-service mathematics teachers to teach in multilingual classrooms: a community of practice perspective (Doctoral dissertation). Witwatersrand University.

Fatmanissa, N., \& Kusnandi, K. (2017). The linguistic challenges of mathematics word problems: A research and literature review. Malaysian Journal of Learning and Instruction, (Special issue on Graduate Students Research on Education), 73-92. https:/ / doi.org/10.32890/mjli.2017.7798

Ferguson, G. (2003). Classroom code-switching in postcolonial contexts: Functions, attitudes and policies. AILA Review, 16(1), 38-51. https://doi.org/ 10.1075/aila.16.05fer

Flevares, L. M., \& Perry, M. (2001). How many do you see? The use of nonspoken representations in firstgrade mathematics lessons. Journal of Educational Psychology, 93(2), 330. https://doi.org/10.1037/ 0022-0663.93.2.330

Franz, D. (2009). Supporting struggling readers in mathematics education. Apex Learning.

Frick, A., \& Newcombe, N. S. (2015). Young children's perception of diagrammatic representations. Spatial Cognition $\mathcal{E}$ Computation, 15(4), 227-245. https:/ / doi.org/10.1080/13875868.2015.1046988

Gafoor, K. A., \& Sarabi, M. K. (2015). Need for equipping student teachers with language of mathematics [Paper presentation]. National Seminar on Pedagogy of Teacher Education - Trends and Challenges.

Gallenstein, N. L. (2005). Engaging young children in science and mathematics. Journal of Elementary Science Education, 17(2), 27.

Gambrell, L. B., \& Jawitz, P. B. (1993). Mental imagery, text illustrations, and children's story comprehension and recall. Reading Research Quarterly, 28(3), 265-276. https:/ / doi.org/10.2307/ 747998

Gerofsky, S. (2009). Genre, simulacra, impossible exchange, and the real: How postmodern theory problematises word problems. In B. Greer, L. Verschaffel, W. van Dooren, \& S. Mukhopadhyay (Eds.), Word and worlds: Modelling verbal descriptions of situations. Sense Publishers. https://doi.org/ 10.1163/9789087909383_003

Gooding, S. (2009). Children's difficulties with mathematical word problems. Proceedings of the British Society for Research into Learning Mathematics, 29(3), 31-36.

Halai, A., \& Karuku, S. (2013). Implementing languagein-education policy in multilingual mathematics classrooms: Pedagogical implications. Eurasia Journal of Mathematics, Science and Technology Education, 9(1), 23-32. https://doi.org/10.12973/ eurasia.2013.913a

Harvey, S., \& Goudvis, A. (2007). Strategies that work teaching comprehension to enhance understanding. Stenhouse Publishers.

Huang, J., \& Normandia, B. (2008). Comprehending and solving word problems in mathematics: Beyond key words. Reading in Secondary Content Areas: A Language-Based Pedagogy, 64-83.

Kaplan, J. J., Rogness, N. T., \& Fisher, D. G. (2014). Exploiting lexical ambiguity to help students understand the meaning of random. Statistics Education Research Journal, 13(1), 9-24.

Kim, H. J. (2020). Concreteness fading strategy: A promising and sustainable instructional model in mathematics classrooms. Sustainability, 12(6), 2211. https:/ / doi.org/10.3390/su12062211

Klerkx, J., Verbert, K., \& Duval, E. (2014). Enhancing learning with visualization techniques. In J. M. Spector, M. D. Merrill, J. Elen, \& M/J. Bishop (Eds.), Handbook of research on educational communications and technology (pp. 791-807). Springer. https: / / doi.org/10.1007/978-1-4614-3185-5_64

Kunene, N., \& Sepeng, P. (2017). Rural learners' views and perceptions about their experiences in word problem solving. Journal of Social Sciences, 50(1-3), 133-140. https:/ / doi.org/10.1080/09718923.2017.1311728

Kurshumlia, R., \& Vula, E. (2013). Mathematics word problem solving for third grade students. In 
Proceedings of the Albania International Conference on Education.

http:/ / dspace.epoka.edu.al/handle/1/804

Larina, G. (2016). Analysis of real-world math problems: Theoretical model and classroom applications. Voprosy Obrazovaniya/Educational Studies Moscow, 3(3), 151.

Lince, R. (2016). Creative thinking ability to increase student mathematical of junior high school by applying models numbered heads together. Journal of Education and Practice, 7(6), 206-212. http:/ / iiste.org/Journals/index.php/JEP

Maher, C., Hadfield, M., Hutchings, M., \& De Eyto, A. (2018). Ensuring rigor in qualitative data analysis: A design research approach to coding combining NVivo with traditional material methods. International Journal of Qualitative Methods, 17(1), 1609406918786362. https:/ / doi.org/10.1177/16094 06918786362

Mahlomaholo, S. (2009). Critical emancipatory research and academic identity. Africa Education Review, 6(2), 224-237.

https:/ / doi.org/10.1080/18146620903274555

Mayaba, N. N. (2009). The effect of a scientific literacy strategy on Grade 6 and 7 learners' general literacy skills (Doctoral dissertation). Nelson Mandela Metropolitan University, Port Elizabeth.

McMillan, J. H., \& Schumacher, S. (2001). Research in education: A conceptual introduction. Longman.

Meulenberg-Buskens, I. (2011). Free attitude interview technique [Unpublished notes].

Mooney, C., Briggs, M., Fletcher, M., Hansen, A., \& McCullouch, J. (2014). Primary mathematics: Teaching theory $\mathcal{E}$ practice. London: SAGE Publications Ltd.

Moriyanti, M., Muna, H., \& Ismail, N. M. (2019). Visualization and comprehension: Corroborating children's reading ability. Englisia: Journal of Language, Education, and Humanities, 7(1), 26-40. https:// doi.org/10.22373/ej.v7i1.4508

Mulligan, J. (2011). Towards understanding the origins of children's difficulties in mathematics learning. Australian Journal of Learning Difficulties, 16(1), 1939. https:/ / doi.org/10.1080/19404158.2011.563476

Mulligan, J., \& Mitchelmore, M. (2009). Awareness of pattern and structure in early mathematical development. Mathematics Education Research Journal, 21(2), 33-49. https://doi.org/10.1007/ BF03217544

Mulwa, E. C. (2015). Difficulties encountered by students in the learning and usage of mathematical terminology: A critical literature review. Journal of Education and Practice, 6(13), 27-37. http:/ /iiste.org/Journals/index.php/JEP
Ní Ríordáin, M., Coben, D., \& Miller-Reilly, B. (2015). What do we know about mathematics teaching and learning of multilingual adults and why does it matter? Adults Learning Mathematics - An International Journal, 10(1), 8-23. https:/ / hdl.handle.net/10289/11407

Nickson, M. (2000). Teaching and learning mathematics: A teacher's guide to recent research and its application. London: Cassell.

Nwachukwu, J. F. (2017). Identifying and improving reading comprehension in the translation process: a visualisation approach (Doctoral dissertation). Stellenbosch University.

Osman, S., Yang, C. N. A. C., Abu, M. S., Ismail, N., Jambari, H., \& Kumar, J. A. (2018). Enhancing students' mathematical problem-solving skills through bar model visualisation technique. International Electronic Journal of Mathematics Education, 13(3), 273-279. https:/ / doi.org/10.12973 /iejme/3919

Phonapichat, P., Wongwanich, S., \& Sujiva, S. (2014). An analysis of elementary school students' difficulties in mathematical problem solving. Procedia - Social and Behavioral Sciences, 116, 3169-3174. https:/ / doi.org/10.1016/j.sbspro.2014.01.728

Sajadi, M., Amiripour, P., \& Rostamy-Malkhalifeh, M. (2013). The examining mathematical word problems solving ability under efficient representation aspect. Mathematics Education Trends and Research, 14, 1-11. https://doi.org/10.5899/ 2013/metr-00007

Seifi, M., Haghverdi, M., \& Azizmohamadi, F. (2012). Recognition of students' difficulties in solving mathematical word problems from the viewpoint of teachers. Journal of Basic and Applied Scientific Research, 2(3), 2923-2928.

Sepeng, P. (2014). Use of common-sense knowledge, language and reality in mathematical word problem solving. African Journal of Research in Mathematics, Science and Technology Education, 18(1), 14-24.

https:/ / doi.org/10.1080/10288457.2014.890808

Shatri, K., \& Buza, K. (2017). The use of visualization in teaching and learning process for developing critical thinking of students. European Journal of Social Science Education and Research, 4(1), 71-74. https:// doi.org/10.26417/ejser.v9i1.p71-74

Taylor, N., \& Vinjevold, P. (1999). Teaching and learning in South African schools. In N. Taylor, \& P. Vinjevold (Eds.), Getting Learning Right: Report to the President's Education Initiative [PEI] Research Project (pp. 131-162). The Joint Education Trust.

Teahen, R. J. (2015). Exploring visualisation as a strategy for improving year 4 E 5 student achievement on mathematics word problems (Master's thesis). Victoria 
University of Wellington. http://hdl.handle.net/ $10063 / 4253$

Tsotetsi, C. T. (2013). The implementation of professional teacher development policies: A continuing education perspective (Doctoral dissertation). University of the Free State.

Vaismoradi, M., Turunen, H., \& Bondas, T. (2013). Content analysis and thematic analysis: Implications for conducting a qualitative descriptive study. Nursing \& Health Sciences, 15(3), 398-405. https:/ / doi.org/10.1111/nhs.12048

Verschaffel, L., Van Dooren, W., Greer, B., \& Mukhopadhyay, S. (2010). Reconceptualising word problems as exercises in mathematical modelling. Journal für Mathematik-Didaktik, 31(1), 9-29. https:/ / doi.org/10.1007/s13138-010-0007-x

Yilmaz, R., \& Argun, Z. (2018). Role of visualization in mathematical abstraction: The case of congruence concept. International Journal of Education in Mathematics, Science and Technology, 6(1), 41-57. https://doi.org/10.18404/ijemst.328337

Ziemkiewicz, C., Ottley, A., Crouser, R. J., Chauncey, K., Su, S. L., \& Chang, R. (2012). Understanding visualization by understanding individual users. IEEE Computer Graphics and Applications, 32(6), 8894. https:/ / doi.org/10.1109/MCG.2012.120

\section{http://www.ejmste.com}

